\title{
Anxiety, Family Functioning and Neuroendocrine Biomarkers in Obese Children
}

\section{Ansiedade, Funcionamento Familiar e Biomarcadores Neuroendócrinos em Crianças Obesas}

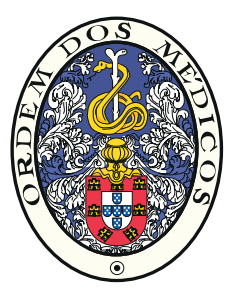

\author{
Inês PINTO $\triangle^{1,2,3}$, Simon WILKINSON ${ }^{4}$, Daniel VIRELLA ${ }^{5}$, Marta ALVES ${ }^{5}$, Conceição CALHAU ${ }^{6,7}$, Rui COELHO $^{8,9}$
} Acta Med Port 2017 Apr;30(4):273-280 - https://doi.org/10.20344/amp.7919

\begin{abstract}
Introduction: This observational study explores potential links between obese children's cortisol, and parental mental state, family functioning, and the children's symptoms of anxiety and depression.

Material and Methods: A non-random sample of 104 obese children (55 boys), mean age 10.9 years (standard deviation 1.76), was recruited from a childhood obesity clinic. Obesity was defined as body mass index above the $95^{\text {th }}$ age- and gender-specific percentiles. Neuroendocrine biomarkers were measured. Symptoms of anxiety and depression were assessed with self and parent-reported questionnaires (Anxiety, Depression and Stress Scales; Child Behaviour Checklist). Family functioning was assessed with parent-reported questionnaires (Family Adaptation and Cohesion Scales-III).

Results: A significant, negative correlation $\left(r_{s}=-0.779 ; p=0.003\right)$ between girls' cortisol and their parents' anxiety symptoms was found, limited to high functioning families. Boys scored significantly higher than girls on parent-reported internalizing symptoms but not on self-report. No association was found between cortisol in children and parental depressive symptoms.

Discussion: Whether the association between cortisol levels in obese children and parental mental health is effectively restricted to girls from high functioning families or is due to study limitations, requires further research. The lack of associations between cortisol in children and parental depressive symptoms, suggests a specific association between cortisol and parental anxiety symptoms.

Conclusion: These results highlight the importance of taking into account family functioning, parental mental state and gender, when investigating neuroendocrine biomarkers in obese children associated with symptoms of anxiety and depression.

Keywords: Anxiety; Biomarkers; Child; Hypothalamo-Hypophyseal System; Pediatric Obesity; Pituitary-Adrenal System; Stress Psychological
\end{abstract}

\section{RESUMO}

Introdução: Este estudo explora relações entre o cortisol em crianças obesas e o estado mental dos pais, o funcionamento familiar e os sintomas de ansiedade e depressão das crianças.

Material e Métodos: Uma amostra de conveniência de 104 crianças obesas (55 rapazes), com idade média de 10,9 anos (desvio padrão 1,76), foi recrutada numa consulta de obesidade infantil. A obesidade foi definida pelo índice de massa corporal acima do percentil 95 ajustado para idade e sexo. Foram medidos biomarcadores neuroendócrinos. Os sintomas de ansiedade e depressão foram avaliados com auto e hetero-questionários (Anxiety, Depression and Stress Scales; Child Behaviour Checklist). O funcionamento familiar foi avaliado através de questionários aos pais (Family Adaptation and Cohesion Scales -III).

Resultados: Observou-se uma correlação negativa significativa $\left(r_{s}=-0,779 ; p=0,003\right)$ entre o cortisol das raparigas de famílias funcionais e os sintomas parentais de ansiedade. Os sintomas internalizantes relatados pelos pais (mas não os auto-relatados) são mais intensos nos rapazes. Não foi encontrada associação entre o cortisol das crianças e os sintomas depressivos dos pais.

Discussão: Não é possível assegurar se a associação entre cortisol sérico nas crianças obesas e sintomas de ansiedade parental se restringe a raparigas de famílias funcionais ou se deve a limitações do estudo. Os achados sugerem uma associação específica entre o cortisol sérico nas crianças obesas e a ansiedade parental.

Conclusão: É importante considerar o género, o funcionamento familiar, o estado mental dos pais ao investigar as associações entre biomarcadores neuroendócrinos em crianças obesas e sintomas de ansiedade e depressão.

Palavras-chave: Ansiedade; Biomarcadores; Criança; Obesidade Pediátrica; Sistema Hipófise-Suprarrenal; Sistema HipotálamoHipofisário; Stress Psicológico

\section{INTRODUCTION}

Symptoms of anxiety and depression are frequent in obese children, ${ }^{1}$ especially in girls, who in addition have metabolic risk. ${ }^{1-3}$ Anxiety, depression and obesity are recognized burdens in both human and economic terms, therefore, it is important to investigate the aetiological

mechanisms involved. ${ }^{4}$ Mental disorders, such as anxiety and depression, produce decrements in public health that are equivalent to those of other chronic physical diseases (e.g., angina, arthritis, asthma, and diabetes). ${ }^{4}$ However, they are stigmatized and regarded as less important. In fact,

\footnotetext{
1. Department of Child and Adolescent Psychiatry. Hospital Beatriz Ângelo. Loures. Portugal.

2. Department of Child and Adolescent Psychiatry. Hospital Dona Estefânia. Centro Hospitalar de Lisboa Central. Lisboa. Portugal.

3. Department of Psychiatry and Mental Health. Faculty of Medicine. University of Porto. Porto. Portugal.

4. Department of Research and Development. Division of Mental Health. Akershus University Hospital. Lørenskog. Norway.

5. Epidemiology and Statistics Office of the Research Unit. Centro Hospitalar de Lisboa Central. Lisboa. Portugal.

6. Nutrition and Metabolism Department. NOVA Medical School. Lisboa. Portugal.

7. Center for Research in Health Technologies and Information Systems. University of Porto. Porto. Portugal.

8. Department of Neurosciences and Mental Health. Faculty of Medicine. University of Porto. Porto. Portugal.

9. Institute for Research and Innovation in Health (i3S). University of Porto. Porto. Portugal.

$\triangle$ Autor correspondente: Inês Pinto. inescopinto@gmail.com

Recebido: 07 de junho de 2016 - Aceite: 10 de novembro de 2016| Copyright @ Ordem dos Médicos 2017
} 
it is not generally acknowledged that, when mental disorders coexist with these physical diseases, the decrease in public health scores is substantially greater than when they occur alone. Thus, a crucial implication follows, that primary health care providers should not ignore the presence of depression and/or anxiety disorders when treating patients with a chronic physical disease. ${ }^{5}$

Metabolic syndrome, of which obesity is a part, shares risk factors with disorders of anxiety and depression. On the other hand, anxiety and depression are also known to increase the risk of obesity. Such a mutually reinforcing relation can contribute to the association between anxiety and depression and coronary artery disease. ${ }^{5}$

Mothers with symptoms of anxiety and depression and their offspring tend to have similar neuroendocrine biomarkers, such as altered levels of cortisol, peripheral levels of dopamine and serotonin, right frontal electroencephalogram activation and vagal tone. ${ }^{6}$ If a description of specific subgroups, such as patients that associate certain biomarkers with specific symptoms, based on such data was to emerge, then, both short and long term benefits of treatment could potentially be improved. Although new reports about treatment response in multisite studies have emerged in the past five years, treatment advances are lagging due to scarcity of adequate studies with the appropriate indicators of response. ${ }^{5}$

Neuroendocrine biomarkers, such as those currently associated with the future development of symptoms of anxiety and depression, seem more frequent in individuals coming from families characterized by intense anxiety and depression. ${ }^{2}$ Moreover, boys and girls living in such families may show differences in their vulnerability to develop symptoms of anxiety and depression themselves. Therefore it is important to take into account the mental state of family members, family functioning and the child's gender, when investigating potential neuroendocrine biomarkers for future anxiety and depression symptoms as found with obesity.

Most strategies for the prevention of childhood obesity are focused on energy balance. ${ }^{7}$ They are directed at behaviours and environments that directly affect energy intake or expenditure, such as increasing physical activity, reducing sedentary behaviour, or limiting intake of high energy foods and beverages. ${ }^{8}$ However, the limited success of these strategies ${ }^{9-11}$ underscores the importance of developing new approaches through identifying other barriers to successful public health strategies.

Given the current state of knowledge, it is reasonable to assume that internalizing symptoms, such as those found with anxiety and depression, may be risk factors for obesity in children. ${ }^{12-14}$ Moreover, it also seems sound and acceptable to consider that obesity be mediated through effects on appetite, sleep, and activity. ${ }^{12-14}$ The (re)activity of the hypothalamic-pituitary-adrenal (HPA)-system plays a role in the course of disorders of anxiety and depression. In the few studies that have investigated the association between anxiety disorders and cortisol levels in children and adolescents, findings have been as inconclusive as in adults. Del Giudice and Shirtcliff ${ }^{6}$ hypothesized that stressful influences in early life may be associated with higher basal levels of cortisol and hyper-responsiveness to subsequent minor stressors provoke frequent elevations in cortisol. The resulting periods of high levels of cortisol are further hypothesized to lead to down-regulation of components of the HPA-system. Another possibility is that under repeated stress, the initial cortisol response becomes modified over the years, so that initial high responses subsequently become lower. ${ }^{15}$ Based on both these possibilities, and on the assumption that long periods of stress in early life would also predispose to future vulnerability for anxiety, we infer that anxiety disorders can be expected to appear in association with lower basal cortisol levels.

Given the current lack of information about causal processes leading to the major health risks associated with both anxiety and depression, and obesity, further research is needed to facilitate the development of both testable hypotheses and the future research agenda. This study aims to explore associations between cortisol levels and symptoms of anxiety and depression in obese children. We hypothesize that gender and family functioning, as characterized by different levels of cohesion and adaptability, play a role together with cortisol levels and symptoms of anxiety and depression in obesity. We also considered whether parental mental state could be associated with family functioning and cortisol levels in obese children.

\section{MATERIAL AND METHODS}

A sample of children attending the Childhood Obesity Paediatric Unit of a tertiary paediatric hospital in Greater Lisbon, was drawn from pre-pubertal obese children recruited for the project Roots of Early Obesity. ${ }^{16}$ The effective sample was based on the children for whom we had detailed records of anthropometric information and behavioural measurements throughout childhood. Exclusion criteria were the use of medication, having already reached puberty during the period of assessment, undergoing mental health intervention or other medical treatment besides those for obesity.

Anxiety and depressive symptoms were assessed using Anxiety, Depression and Stress Scales (EADS) such as 'EADS-C - Escala de Ansiedade, depressão e stresse para crianças', child-version; and 'EADS - Escala de Ansiedade, depressão e stresse', adult-version. EADS-C and EADS are self-report questionnaires validated for Portugal. ${ }^{17,18}$ The EADS-C and EADS are a set of three self-reported scales (21-items) designed to measure symptoms of depression (dysphoria, hopelessness, devaluation of life, self-depreciation, lack of interest/involvement, anhedonia, and inertia), anxiety (autonomic arousal, skeletal muscle effects, situational anxiety, and feeling anxious) and stress (difficulty relaxing, hypervigilant, and being easily upset/agitated, irritable/over-reactive and impatient). The responses are classified according to four levels: 0) never happens; 1) happens sometimes; 2) happens very often; and 3 ) happens almost all the time. EADS-C has a structure 
similar to the adult version ${ }^{18}$ although the load values of the items in each dimension are less discriminative than in adults. ${ }^{17}$

The Child Behaviour Checklist (CBCL $6-18)$ is a parent-reported questionnaire for assessing behavioural or emotional problems in children and adolescents (aged 6 to 18 year olds). It contains 120 items on behavioural or emotional problems experienced in the six months prior to the test. These items are scored on a three point scale: $0=$ not true; 1 = somewhat or sometimes true; 2 = very or often true.

The CBCL version used is approved by Achenbach (http://www.aseba.org/ordering/translations.html). ${ }^{19}$ This instrument is used to explore internalizing and externalizing symptoms. As conceived by Achenbach (1991), internalizing symptoms refer to three categories: withdrawal, somatic complaints, and anxiety/depression. Externalizing symptoms refer to the categories of delinquent and aggressive behaviour.

Family functioning was assessed using Family Adaptation and Cohesion Scales (FACES) III, ${ }^{20}$ a parentreported questionnaire, validated for Portugal. ${ }^{20}$ Only one parent per child participated, most often the mother. This self-reported 20-item Lykert type questionnaire evaluates two major dimensions (Cohesion and Family Adaptation) on a circumplex model, which is integral to the conceptualisation of functioning employed in FACES. Reliability for Cohesion is 0.78 and for Family Adaptation is $0.70 .{ }^{20}$

Cohesion is conceptualised as the emotional closeness that family members have to one another. Adaptability is conceptualised as the potential for change in family leadership, role relationship, and relationship rules. FACES assesses the degree to which family members are adaptive and connected to each other. The dimension of family adaptability is categorised into four 'levels' of functioning: rigid, structured, flexible, and chaotic. The two middle levels (structured and flexible) are considered as balanced family adaptability and the two extreme levels (rigid and chaotic) are considered as unbalanced levels of family adaptability. The dimension of family cohesion is categorised into four 'levels' of functioning: disengaged, separated, connected, and enmeshed. Similar to that for family adaptability, the two middle levels (separated and connected) are considered to be balanced levels of family cohesion and the two extreme levels (disengaged and enmeshed) are considered to be unbalanced levels of family cohesion. ${ }^{20}$ In other words, balanced levels of cohesion and adaptability are conceptualised as reflecting healthier family functioning, and they are classified as 'high functioning families'. Unbalanced levels of cohesion and adaptability (very low or very high levels) are seen as reflecting more problematic family functioning, and they are classified as 'low functioning families'.

Height, weight, waist circumference, blood pressure and heart rate were measured following standardized protocols. Obesity was defined as BMI $\left(\mathrm{kg} \cdot \mathrm{m}^{-2}\right)$ above the $95^{\text {th }}$ age and gender-specific percentile. ${ }^{21}$ Overweight was defined as BMI $\left(\mathrm{kg} \cdot \mathrm{m}^{-2}\right)$ above the $85^{\text {th }}$ age- and gender-specific percentile. ${ }^{21}$ Blood pressure was measured three times and the third reading was recorded. ${ }^{21}$ Age and gender-specific percentiles were used. ${ }^{21}$

As part of the Roots of Early Obesity project, ${ }^{16}$ fasting blood samples were drawn at 8 a.m. through an indwelling catheter, after 45 minuntes of rest. Plasma cortisol, glucose, insulin, high density lipoprotein (HDL) and low density lipoprotein (LDL) cholesterol, triglycerides and catecholamines were measured using the standard procedures of the Clinical Pathology Laboratory of the institution.

Parental written, informed consent was obtained. The project was approved by the Hospital Medical Ethics Committee.

To investigate the nature of the relation between cortisol levels, and symptoms of anxiety and depression (modelled as ordinal variables), Spearman correlation analyses and significance tests were performed, both with respect to the global sample and to each of its above mentioned subgroups. ${ }^{21}$ Data analysis was performed using the software SPSS 22.0. ${ }^{22}$

\section{RESULTS}

A sample of 104 recruited pre-pubertal children (55 boys), with mean age of 10.88 years (standard deviation 1.76) was included in the analysis. BMI was calculated for 63 children, of whom 59 were obese (35 boys) and four were overweight (one boy). Waist circumference was measured in 46 children, with median $\left(P_{25}-P_{75}\right)$ of $90.5 \mathrm{~cm}$ (76.8 - 97.1). Hypertension was diagnosed in 13 out of 59 assessed children.

The values found for the symptom scores (anxiety, depression and internalizing symptoms, which included anxiety and depression in Achenbach's CBCL system) and

Table 1 - Symptom scores (anxiety, depression and internalizing symptoms) as median $\left(\mathrm{P}_{25}-\mathrm{P}_{75}\right)$ for the whole sample

\begin{tabular}{ll}
\hline Measures & Symptom scores \\
\hline EADS & $10.0(2.0-17.0)$ \\
Anxiety symptoms & \\
$n=71$ & $13.0(5.0-24.0)$ \\
EADS & \\
Depression symptoms & \\
$n=71$ & $17.0(2.5-45.5)$ \\
EADS-C & \\
Anxiety symptoms & \\
$n=76$ & $20.0(6.0-58.0)$ \\
EADS-C & \\
Depression symptoms & \\
$n=76$ & $11.0(7.0-15.0)$ \\
CBCL & \\
Internalizing symptoms & \\
$n=65$ & $9.0(3.5-16.0)$ \\
CBCL & \\
Externalizing symptoms & \\
$n=65$ & \\
\hline
\end{tabular}

EADS-C: Escala de ansiedade, depressão e stresse, child version; EADS: Escala de ansiedade, depressão e stresse, adult version; CBCL: Child Behaviour Checklist 
Table 2 - Descriptives of the neuroendocrine and metabolic biomarkers values

\begin{tabular}{|c|c|c|c|c|}
\hline Parameter (n) & Mean (SD) & Median & Min. - Max. & $P_{25}-P_{75}$ \\
\hline Glucose (mg/dL) (57) & $92.5(15.4)$ & 93.0 & $1-120$ & $89.0-98.0$ \\
\hline Insulin (U/mL) (43) & $14.55(9.60)$ & 13.4 & $0.28-52.95$ & $7.99-16.92$ \\
\hline Triglycerides (mg/dL) (51) & $97.21(39.80)$ & 89.0 & $33-187$ & $68.0-129.0$ \\
\hline Cholesterol (mg/dL) (53) & $161.85(31.00)$ & 166.0 & $49-227$ & $145.0-184.0$ \\
\hline $\mathrm{HDL}(\mathrm{mg} / \mathrm{dL})(50)$ & $48.80(13.87)$ & 47.0 & $24-91$ & $38.0-57.3$ \\
\hline LDL (mg/dL) (48) & $107.93(23.51)$ & 109.5 & $59-167$ & $95.0-118.5$ \\
\hline ALT (U/L) (50) & $28.20(23.42)$ & 23.0 & $11-167$ & $17.0-30.0$ \\
\hline AST (U/L) (48) & $24.10(7.44)$ & 24.5 & $12-56$ & $19.0-26.8$ \\
\hline $\mathrm{TSH}(\mu \mathrm{IU} / \mathrm{mL})(56)$ & $2.74(1.17)$ & 2.6 & $0.72-5.92$ & $1.8-3.5$ \\
\hline T4 (ng/dL) (53) & $1.27(2.11)$ & 1.0 & $0.59-16.20$ & $0.8-1.2$ \\
\hline ACTH (pg/mL) (68) & $28.89(20.67)$ & 20.7 & $5.35-118.0$ & $16.3-35.2$ \\
\hline Cortisol( $\mu \mathrm{g} / \mathrm{dL})(53)$ & $10.8(5.16)$ & 9.95 & $3.3-29.0$ & $7.2-13.6$ \\
\hline Dopamine urine $(\mu \mathrm{g} / \mathrm{dL})(18)$ & $236.8(128.07)$ & 236.8 & $45.0-513.8$ & $145.6-348.4$ \\
\hline Dopamine plasma $(\mu \mathrm{g} / \mathrm{dL})(12)$ & $115.6(150.40)$ & 37.3 & $6.0-510.96$ & $24.8-205.40$ \\
\hline Epinephrine urine ( $\mu \mathrm{g} / \mathrm{dL})(17)$ & $6.7(7.36)$ & 5.99 & $0.5-32.5$ & $3.5-7.65$ \\
\hline Epinephrine plasma( $\mu \mathrm{g} / \mathrm{dL})(12)$ & $5.4(9.66)$ & 0.7 & $0.09-32.5$ & $0.4-6.8$ \\
\hline Norepinephrine urine $(\mu \mathrm{g} / \mathrm{dL})(17)$ & $34.2(25.46)$ & 30.7 & $5.9-105.8$ & $17.5-47.7$ \\
\hline Norepinephrine plasma $(\mu \mathrm{g} / \mathrm{dL})(12)$ & $15.8(23.47)$ & 5.8 & $0.8-81.4$ & $2.4-19.1$ \\
\hline
\end{tabular}

Glucose: Basal plasma glucose; Max.: Maximum; Min.: Minimum; n: Number of assessed children; P: Percentile; SD: Standard deviation.

neuroendocrine and metabolic biomarkers in the complete sample are presented as Tables 1 and 2.

The distribution of symptom scores and serum cortisol levels in the whole sample showed no significant differences between either high and low functioning families, or between boys and girls, but the score (median, $\mathrm{P}_{25}-\mathrm{P}_{75}$ ) for internalizing symptoms $(\mathrm{CBCL})$ showed a tendency to be higher in boys $(12.5,9.0-15.0$ vs $9.0,6.5-13.5$; Mann-Whitney, $p=0.066$ ) (see also Table 3). An interesting observation, which nevertheless lead to no changes in cortisol, was that parents of obese boys scored (median, $\mathrm{P}_{25}-\mathrm{P}_{75}$ ) markedly higher, as close to significance as it is possible to get, for depression symptoms (EADS) compared to parents of obese girls $(28,10$ - 66 vs 10, 0-38; MannWhitney, $p=0.051$ ).

Serum cortisol levels in girls had a significant $(p=0.026)$ but low $\left(r_{s}=-0.464\right)$ negative correlation with parent-reported anxiety score (EADS) (Table 4). Nearly significant negative low correlations were found between serum cortisol levels and parent-reported anxiety score (EADS) in children from low functioning families, child-reported anxiety score (EADS-C) in children from high functioning families and the score for externalizing symptoms (CBCL) in girls (Table 4).

The distribution of symptom scores and cortisol levels according to gender and family functioning is presented in Table 1. Girls from low functioning families scored significantly lower for internalizing problems $(C B C L)$ than boys from both high (Kruskal-Wallis, $p=0.039$ ) and low (Kruskal-Wallis, $p=0.018$ ) functioning families but scored similarly to females from high functioning families (Table 3). No significant differences were found when considering BMI categories.
Table 5 shows the results for the correlation analyses and significance tests between serum cortisol levels and symptom scores (anxiety, depression, internalizing and externalizing symptoms), for each of the four subgroups (according to gender and family functioning). There was a significant, negative correlation between obese girls' cortisol and their parents' self-reported anxiety symptoms limited to high functioning families $\left(r_{s}=-0.779 ; p=0.003\right)$. No association was found between child serum cortisol and parental self-reported depressive symptoms.

\section{DISCUSSION}

This study explores associations between basal serum cortisol levels and symptoms of anxiety and depression in a sample of obese children. We found a significant negative association between serum cortisol and the parents' anxiety symptoms, limited to girls and particularly significant for girls from high functioning families. Boys scored significantly higher for parent-reported internalizing symptoms than girls. Parents of obese boys scored markedly higher for symptoms of depression than parents of obese girls. No associations were found between the children's serum cortisol and their parents' depressive symptoms, indicating that the association that was found between serum cortisol and parents' anxiety symptoms was specific for anxiety.

One possible explanation for this association between parents' anxiety symptoms and children's cortisol levels is that it is secondary to alterations in HPA-system activity present from birth. HPA-system functioning is at least partially determined by genetic ${ }^{23,24}$ and prenatal factors. ${ }^{25}$ For example, corticotrophic releasing hormone (CRH) gene regulation involves multiple activating and repressing 
Table 3 - Symptom scores (anxiety, depression and internalizing symptoms) and cortisol levels as median $\left(P_{25}-P_{75}\right)$, according to gender and family functioning

\begin{tabular}{lllll}
\hline \multirow{2}{*}{ Measures } & \multicolumn{2}{l}{ High functioning family } & \multicolumn{2}{l}{ Low functioning family } \\
& Boys & Girls & Boys & Girls \\
\hline EADS & $10.0(2.0-21.8)$ & $7.0(2.0-17.5)$ & $14.0(10.0-19.0)$ & $3.5(1.5-26.8)$ \\
Anxiety symptoms & $\mathrm{n}=18$ & $\mathrm{n}=17$ & $\mathrm{n}=11$ & $\mathrm{n}=6$ \\
EADS & $14.0(4.5-32.3)$ & $17.0(2.5-24.0)$ & $14.0(6.0-21.0)$ & $19.0(0-44.5)$ \\
Depression symptoms & $\mathrm{n}=18$ & $\mathrm{n}=17$ & $\mathrm{n}=11$ & $\mathrm{n}=6$ \\
CBCL & $12.0(9.5-14.5)$ & $11.0(8.0-16.0)$ & $14.0(9.0-22.0)$ & $5.0(2.0-7.5)$ \\
Internalizing symptoms & $\mathrm{n}=17$ & $\mathrm{n}=15$ & $\mathrm{n}=10$ & $\mathrm{n}=5$ \\
Cortisol (ug/dL) & $8.5(6.7-11.7)$ & $10.6(6.8-13.0)$ & $11.2(8.8-16.8)$ & $15.2(5.8-17.5)$ \\
& $\mathrm{n}=14$ & $\mathrm{n}=13$ & $\mathrm{n}=9$ & $\mathrm{n}=4$ \\
\hline
\end{tabular}

EADS: Escala de ansiedade, depressão e stresse, adult version; CBCL: Child Behaviour Checklist

Table 4 - Correlation of cortisol levels (ug/L) with anxiety, depression, internalizing and externalizing symptoms, for each subgroup of the sample

\begin{tabular}{llllll}
\hline & Boys & Girls & High functioning family & Low functioning family & Obese children \\
\hline EADS-C & $r_{\mathrm{s}}=-0.043$ & $r_{\mathrm{s}}=-0.149$ & $r_{\mathrm{s}}=0.479$ & $r_{\mathrm{s}}=-0.308$ & $r_{\mathrm{s}}=-0.191$ \\
Anxiety symptoms & $\mathrm{p}=0.832$ & $p=0.519$ & $p=0.071$ & $\mathrm{p}=0.356$ & $\mathrm{n}=0.321$ \\
& $\mathrm{n}=27$ & $\mathrm{n}=21$ & $\mathrm{n}=15$ & $\mathrm{n}=29$ \\
EADS-C & $r_{\mathrm{s}}=-0.080$ & $r_{\mathrm{s}}=-0.095$ & $r_{\mathrm{s}}=0.355$ & $r_{\mathrm{s}}=-0.185$ & $r_{\mathrm{s}}=-0.284$ \\
Depression symptoms & $p=0.692$ & $p=0.683$ & $p=0.194$ & $\mathrm{n}=11$ & $\mathrm{p}=0.136$ \\
& $\mathrm{n}=27$ & $\mathrm{n}=21$ & $\mathrm{n}=15$ & $r_{\mathrm{s}}=-0.485$ & $\mathrm{n}=29$ \\
EADS & $r_{\mathrm{s}}=0.149$ & $r_{\mathrm{s}}=-0.464$ & $r_{\mathrm{s}}=-0.328$ & $p=0.093$ & $r_{\mathrm{s}}=-0.096$ \\
Anxiety symptoms & $p=0.442$ & $p=0.026$ & $p=0.102$ & $\mathrm{n}=13$ & $\mathrm{p}=0.628$ \\
& $\mathrm{n}=29$ & $\mathrm{n}=23$ & $\mathrm{n}=26$ & $r_{\mathrm{s}}=0.103$ & $\mathrm{n}=28$ \\
EADS & $r_{\mathrm{s}}=0.064$ & $r_{\mathrm{s}}=-0.016$ & $r_{\mathrm{s}}=-0.081$ & $\mathrm{n}=13$ & $r_{\mathrm{s}}=0.113$ \\
Depression symptoms & $p=0.742$ & $p=0.943$ & $p=0.692$ & $r_{\mathrm{s}}=-0.019$ & $\mathrm{p}=0.565$ \\
& $\mathrm{n}=29$ & $\mathrm{n}=23$ & $\mathrm{n}=26$ & $\mathrm{n}=28$ \\
CBCL & $r_{\mathrm{s}}=0.001$ & $r_{\mathrm{s}}=0.121$ & $r_{\mathrm{s}}=0.331$ & $r_{\mathrm{s}}=-0.080$ \\
Internalizing symptoms & $p=0.995$ & $p=0.583$ & $p=0.114$ & $\mathrm{n}=13$ & $p=0.684$ \\
& $\mathrm{n}=27$ & $\mathrm{n}=23$ & $\mathrm{n}=24$ & $r_{\mathrm{s}}=-0.225$ & $\mathrm{n}=28$ \\
CBCL & $r_{\mathrm{s}}=0.174$ & $r_{\mathrm{s}}=-0.375$ & $r_{\mathrm{s}}=0.021$ & $\mathrm{p}=0.460$ & $r_{\mathrm{s}}=-0.166$ \\
Externalizing symptoms & $p=0.386$ & $p=0.078$ & $p=0.924$ & $\mathrm{n}=13$ & $p=0.399$ \\
& $\mathrm{n}=27$ & $\mathrm{n}=23$ & $\mathrm{n}=24$ & $\mathrm{n}=28$ \\
\hline
\end{tabular}

EADS-C: Escala de ansiedade, depressão e stresse, child version; EADS: Escala de ansiedade, depressão e stresse, adult version; CBCL: Child Behaviour Checklist; $r_{\mathrm{s}}$ : Spearman correlation coefficient; $p$ : Significance level, $\mathrm{n}$ : Number of children per correlation

transcription factors, specifically the glucocorticoid receptors and cyclic adenosine monophosphate (cAMP). Another important biological aspect is timing in the transcription of the signals, which is critical for effective glucocorticoid (GC) repression of the cAMP induced $\mathrm{CRH}$ gene. ${ }^{24}$ Therefore, differences in timing of stimulatory and repression signals may be important for adaptation of the organism to stress, thereby providing a molecular explanation for the variability in adaptation to stress. These factors may influence $\mathrm{CRH}$ secretion patterns, ${ }^{26}$ feedback effects of cortisol on central $\mathrm{GC}$ receptors, or both. ${ }^{24}$

On theoretical grounds, one can expect alterations in HPA-system activity to be more evident in individuals with a long history of anxiety symptoms. These changes may be reasonably interpreted as expressing a state of accrued vulnerability which is akin to some increment in maternal stress, in particular, during the latter half of pregnancy. Such undesirable conditions are known to favour maternal weight gain during pregnancy. ${ }^{27}$ An overactive HPA-system leading to elevated cortisol levels is associated with an increased prevalence of abdominal obesity, although previous studies have suggested that there are obese individuals who may have desensitization to glucocorticoids, thereby not exhibiting increased blood cortisol. ${ }^{24} \mathrm{~A}$ well accepted hypothesis is that once the HPA-system is over-activated during early development, it remains permanently unstable, vulnerable or dysfunctional, possibly due to transcriptional/ epigenomic mechanisms. ${ }^{28}$

These elevations could influence down-regulation of components of the HPA-system, as suggested by the Adaptive Calibration Model, ${ }^{6}$ an evolutionary-developmental theory of individual differences in the functioning of the stress response system. HPA activity is regulated by a hierarchy of feedback loops at different levels in the axis, and the sensitivity of these feedback loops is a major factor in determining HPA responsivity. The HPA-system responds to chronic stressors with sustained cortisol elevation, resulting in a flattened diurnal rhythm of secretion. Chronic elevation is often followed by a negative rebound of the system to below the previous baseline level after the stressor terminates. This hypocortisolism phase can last months; its function is probably to facilitate recovery and offset the physiological and immune costs of high circulating cortisol. ${ }^{6}$ Hence, high and persistent levels of anxiety could 
Table 5 - Rank correlation analyses between serum cortisol levels and symptom scores (anxiety, depression, internalizing and externalizing symptoms), for each subgroups (according to gender and family functioning) of the sample

\begin{tabular}{|c|c|c|c|c|}
\hline & \multicolumn{2}{|c|}{ High functioning family } & \multicolumn{2}{|c|}{ Low functioning family } \\
\hline & Boys & Girls & Boys & Girls \\
\hline $\begin{array}{l}\text { Anxiety symptoms } \\
\text { (EADS-C) }\end{array}$ & $\begin{array}{l}r_{\mathrm{s}}=0.546 \\
p=0.205 \\
\mathrm{n}=7\end{array}$ & $\begin{array}{l}r_{\mathrm{s}}=0.374 \\
p=0.362 \\
\mathrm{n}=8\end{array}$ & $\begin{array}{l}r_{\mathrm{s}}=-0.132 \\
p=0.778 \\
\mathrm{n}=7\end{array}$ & $\begin{array}{l}r_{\mathrm{s}}=-0.800 \\
p=0.200 \\
\mathrm{n}=4\end{array}$ \\
\hline $\begin{array}{l}\text { Depression symptoms } \\
\text { (EADS-C) }\end{array}$ & $\begin{array}{l}r_{\mathrm{s}}=0.577 \\
p=0.175 \\
\mathrm{n}=7\end{array}$ & $\begin{array}{l}r_{\mathrm{s}}=0.195 \\
p=0.643 \\
\mathrm{n}=8\end{array}$ & $\begin{array}{l}r_{\mathrm{s}}=-0.019 \\
p=0.968 \\
\mathrm{n}=7\end{array}$ & $\begin{array}{l}r_{\mathrm{s}}=-1.000 \\
- \\
\mathrm{n}=4\end{array}$ \\
\hline $\begin{array}{l}\text { Anxiety symptoms } \\
\text { (EADS) }\end{array}$ & $\begin{array}{l}r_{\mathrm{s}}=0.151 \\
p=0.607 \\
\mathrm{n}=14\end{array}$ & $\begin{array}{l}r_{\mathrm{s}}=-0.779 \\
p=0.003 \\
\mathrm{n}=12\end{array}$ & $\begin{array}{l}r_{\mathrm{s}}=-0.313 \\
p=0.412 \\
\mathrm{n}=9\end{array}$ & $\begin{array}{l}r_{\mathrm{s}}=-0.316 \\
p=0.684 \\
\mathrm{n}=4\end{array}$ \\
\hline $\begin{array}{l}\text { Depression symptoms } \\
\text { (EADS) }\end{array}$ & $\begin{array}{l}r_{\mathrm{s}}=0.144 \\
p=0.624 \\
\mathrm{n}=14\end{array}$ & $\begin{array}{l}r_{\mathrm{s}}=-0.293 \\
p=0.355 \\
\mathrm{n}=12\end{array}$ & $\begin{array}{l}r_{\mathrm{s}}=-0.076 \\
p=0.846 \\
\mathrm{n}=9\end{array}$ & $\begin{array}{l}r_{\mathrm{s}}=0.738 \\
p=0.262 \\
\mathrm{n}=4\end{array}$ \\
\hline $\begin{array}{l}\text { Internalizing symptoms } \\
\text { (CBCL) }\end{array}$ & $\begin{array}{l}r_{\mathrm{s}}=0.346 \\
p=0.247 \\
\mathrm{n}=13\end{array}$ & $\begin{array}{l}r_{\mathrm{s}}=0.347 \\
p=0.296 \\
\mathrm{n}=11\end{array}$ & $\begin{array}{l}r_{\mathrm{s}}=0.139 \\
p=0.721 \\
\mathrm{n}=9\end{array}$ & $\begin{array}{l}r_{\mathrm{s}}<0.001 \\
p=1.000 \\
\mathrm{n}=4\end{array}$ \\
\hline $\begin{array}{l}\text { Externalizing symptoms } \\
\text { (CBCL) }\end{array}$ & $\begin{array}{l}r_{\mathrm{s}}=0.483 \\
p=0.094 \\
\mathrm{n}=13\end{array}$ & $\begin{array}{l}r_{\mathrm{s}}=-0.474 \\
p=0.141 \\
\mathrm{n}=11\end{array}$ & $\begin{array}{l}r_{\mathrm{s}}=0.030 \\
p=0.940 \\
\mathrm{n}=9\end{array}$ & $\begin{array}{l}r_{\mathrm{s}}=-0.316 \\
p=0.684 \\
\mathrm{n}=4\end{array}$ \\
\hline
\end{tabular}

EADS-C: Escala de ansiedade, depressão e stresse, child version; EADS: Escala de ansiedade, depressão e stresse, adult version; CBCL: Child Behaviour Checklist; $r_{\mathrm{s}}$ : Spearman correlation coefficient; $p$ : Significance level; $\mathrm{n}$ : Number of children per correlation

be associated with low cortisol concentrations, reflecting resilience rather than a risk for psychopathology. ${ }^{29}$

This is in accordance with the present study's findings for girls. We found a significant negative association between serum cortisol and parents' anxiety symptoms, limited to girls, and particularly significant for girls from high functioning families.

Family functioning might operate through either a threshold effect, or be secondary to reduced buffering effects of protective relationships. ${ }^{7}$ Possibly parents with high levels of anxiety symptoms influence their children's vulnerability to anxiety symptoms through an excess of control. In fact, some overprotective parenting behaviour has been associated with increased risk for anxiety symptoms in children. ${ }^{30,31}$ In the group from low functioning families, the association between parents' anxiety symptoms and cortisol was not found to be statistically significant. However, this limitation may well be just a reflection of the small sample sizes of children for whom complete data-sets were obtained (Table 5). It is also proposed that affects are 'infectious' and mirror neurone influences may be at play so that the affective state of the parent is contagious. We already know that successful treatment of a depressive disorder in adolescents depends on treating any concomitant parental depressive disorder at the same time. But we are unaware of studies having looked at the same for anxiety.

There is another possibility to explain the slightly paradoxical finding of a relationship between higher functioning, parental anxiety symptoms and girls' cortisol. The findings depend on self-reports from the parents, and it may be that parents from lower functioning families, particularly those high on rigidity and disengaged, are less clear about reporting on their subjective affective states. The relation between family functioning and quality of the self-reported information needs further investigation. Nevertheless there is a definite relation between parental mental state and biomarkers in their children. Future research needs to look at whether there is a connection between parental mental state, parental awareness of their children's diverse forms of distress, including those of anxiety and depression, and family functioning. The finding about lower reporting of internalizing symptoms in girls from low functioning families, may also be a result of lower parental awareness of their daughters' subjective discomforts, rather than an absolute finding that these girls had actually less internalizing distress. Parents of obese boys scored markedly higher for symptoms of depression than parents of obese girls.

On the other hand, investigating the role of genetic, epigenetic, attachment strategies and their interactions was beyond the scope of the present study. The role of attachment strategies is addressed elsewhere. ${ }^{32}$

The areas of the brain that govern energy balance are also involved in the response to stress and in emotion regulation. Extreme and/or sustained stress is associated with disregulation of energy balance. ${ }^{13,28,33}$ Protection against obesity may arise by improving children's ability to modulate their metabolic and behavioural responses to stress. Thus educated, they would be able to read their body signals, both implicit and explicit, and use the signals more appropriately to achieve a greater state of well-being, harnessing their needs. Children whose stress response is well regulated may be less likely, for example, to overeat in response to emotional distress, and may have longer sleep duration, which could also reduce their risk for obesity. ${ }^{29,34}$

\section{Strengths and limitations}

Our goal was to contribute to understand the complexity 
of a wide range of associations with cortisol levels in obese children. The study was not designed to test hypotheses, include all possible relevant parameters or be designed to generalize the findings to other samples. Through identifying discrete subsamples it may be possible to identify factors that only have effects under limited circumstances. But our study size means that such subsamples were of necessity very small.

In this study, HPA-system activity was not directly assessed in response to a stressor. The results do not reflect absolute changes in cortisol levels but shifts in the diurnal rhythm which itself might not be constant when there is anxiety or depression. Thus, future studies that assess both measures simultaneously may reveal more differentiated, results. The ethical dilemma arise with exposing children to prospective stress, and it may be that one would have to be limited to such situations as arise with starting at a new school or similar.

The findings depend on self-reports primarily from the mothers, rather than both parents, and it may be that parents from lower functioning families are less clear about reporting on their subjective affective states. The FACES dimensions suggest different forms of low functioning, ie low in quality, but including dimensionally opposite extremes. The study cannot elaborate on this. Within the attachment paradigm we would expect the outliers to be a mixture of those who overemphasise their discomforts (Type C), and those who have always displayed little of their affective states, and been poorly aware of what they might be (Type A). The relation between family functioning and quality of the self-reported information underlines the importance of using multiple sources providing both self-report and observations, also while investigating neuroendocrine biomarkers of anxiety and depression. ${ }^{35}$

If specific subgroups based on patients in whom there are different associations between biomarkers and specific symptoms emerges, then, both short and long term benefits of treatment could potentially be improved.

Due to the exploratory nature of this project, it was only possible to identify a few discrete subsamples from which it

\section{REFERENCES}

1. Anderson S, Gooze R, Lemeshow S, Whitaker R. Quality of early maternal child relationship and risk of adolescent obesity. Pediatrics. 2011;129:132-40.

2. Wehry A, Beesdo-Baum K, Hennelly M, Connolly S, Strawn J. Assessment and treatment of anxiety disorders in children and adolescents. Curr Psychiatry Rep. 2015;17:591.

3. Esposito M, Gallai B, Roccella M, Marotta R, Lavano F, Lavano SM, et al. Anxiety and depression levels in prepubertal obese children: a casecontrol study. Neuropsychiatr Dis Treat. 2014;10:1897-902

4. Padula WV, Allen RR, Nair KV. Determining the cost of obesity and its common comorbidities from a commercial claims database. Clin Obes. 2014;4:53-8

5. Kupfer D, Frank E, Phillips M. Major depressive disorder: new clinical, neurobiological, and treatment perspectives. Lancet. 2012;379:104555.

6. Del Giudice M, Ellis BJ, Shirtcliff EA. The adaptive calibration model of stress responsivity. Neurosci Biobehav Rev. 2011;35:1562-92.

7. Sabin MA, Kiess W. Childhood obesity: current and novel approaches. Best Pract Res Clin Endocrinol Metab. 2015;29:327-38. seems possible to gain further insight into the role of factors that under certain circumstances contribute to the symptom constellation.

\section{CONCLUSION}

These results highlight the importance of taking into account family functioning, parental mental state and gender, when investigating neuroendocrine biomarkers associated with symptoms of anxiety and depression in obese children. We present empirical evidence that the harnessing of such a complex, mutually reinforcing dynamic across generations may open the way to the identification of relevant neuroendocrine biomarkers and, thereby, open the horizon for the design of effective preventive strategies.

\section{ACKNOWLEDGEMENTS}

We are very grateful for the cooperation and interest of Hospital Dona Estefânia, Centro Hospitalar de Lisboa Central, EPE.

\section{PROTECTION OF HUMANS AND ANIMALS}

The authors declare that the procedures were followed according to the regulations established by the Clinical Research and Ethics Committee and to the Helsinki Declaration of the World Medical Association.

\section{DATA CONFIDENTIALITY}

The authors declare having followed the protocols in use at their working center regarding patient's data publication.

\section{CONFLICTS OF INTEREST}

The authors declare that there are no conflicts of interest.

\section{FUNDING SOURCES}

The project was supported by the Research Support Scheme of the FMUP/doctoral program, grant no PEst-OE/ SAU/UI0038/2011 and by FCT, SFRH/SINTD/60115/2009, FSE-UE.

8. Horodyska K, Luszczynska A, van den Berg M, Hendriksen M, Roos G, De Bourdeaudhuij I, et al. Good practice characteristics of diet and physical activity interventions and policies: an umbrella review. BMC Public Health. 2015;15:19.

9. Ciampa PJ, Kumar D, Barkin SL, Sanders LM, Yin HS, Perrin EM, et al. Interventions aimed at decreasing obesity in children younger than 2 years: a systematic review. Arch Pediatr Adolesc Med. 2010;164:1098104.

10. Hesketh KD, Campbell KJ. Interventions to prevent obesity in 0-5 year olds: an updated systematic review of the literature. Obesity. 2010;18:S27-35

11. Whitlock EP, O'Connor EA, Williams SB, Beil TL, Lutz KW. Effectiveness of weight management interventions in children: a targeted systematic review for the USPSTF. Pediatrics. 2010;125:396-418.

12. Maniam J, Antoniadis C, Morris MJ. Early-life stress, HPA axis adaptation, and mechanisms contributing to later health outcomes. Front Endocrinol. 2014;5:73.

13. Lee YA, Yamaguchi Y, Goto Y. Neurodevelopmental plasticity in pre- and postnatal environmental interactions: implications for 
psychiatric disorders from an evolutionary perspective. Neural Plast. 2015;2015:291476.

14. He F, Bixler EO, Berg A, Kawasawa $Y$, Vgontzas AN, FernandezMendoza $\mathrm{J}$, et al. Habitual sleep variability, not sleep duration, is associated with caloric intake in adolescentes. Sleep Med. 2015;16:85661.

15. Van der Vegt EJ; van der Ende J, Huizink AC, Verhulst FC, Tiemeier H. Childhood adversity modifies the relationship between anxiety disorders and cortisol secretion. Biol Psychiatry. 2010;1;68:1048-54.

16. Pinto I, Calhau C, Coelho R. Childhood obesity: the role of family factors, depressive symptoms and anxiety levels. Int J Obes. 2011; 35,1010.

17. Leal I, Antunes R, Pais-Ribeiro J, Maroco J. Estudo da escala de depressão ansiedade e stresse para crianças (EADS-C). Psicol Saúde Doenças. 2009;10:277-86.

18. Pais Ribeiro J, Honrado A, Leal I. Contribuição para o estudo da adaptação portuguesa das escalas de ansiedade, depressão e stress (EADS) de 21 itens de Lovibond e Lovibond. Psicol Saúde Doenças. 2004:5:229-39.

19. Gonçalves M, Simões M. O modelo multiaxial de Achenbach (ASEBA) na avaliação clínica de crianças e adolescentes. In: Soares I, editor. Psicopatologia do desenvolvimento: trajectorias (in) adaptativas ao longo da vida. Coimbra: Quarteto; 2000. p.11-42.

20. Curral R, Dourado F, Roma-Torres A, Barros H, Pacheco Palha A, Almeida L. Coesão e adaptabilidade familiares numa amostra portuguesa: estudo com o FACES III. Psiquiatr Clin. 1999;20-3.

21. WHO Multicentre Growth Reference Study Group. WHO Child Growth Standards: length/height-for-age, weight-for-age, weight-forlength, weight-for-height and body mass index-for-age: methods and development. Geneva: WHO; 2006.

22. SPSS for Windows, Rel. 22.0.1.2013. SPSS Inc., Chicago, I, EUA.

23. Dedovic K, Ngiam J. The cortisol awakening response and major depression: examining the evidence. Neuropsychiatr Dis Treat. 2015;11:1181-9.
24. Pasquali R. The hypothalamic-pituitary-adrenal axis and sex hormones in chronic stress and obesity: pathophysiological and clinical aspects. Ann N Y Acad Sci. 2012;1264:20-35.

25. Radtke KM, Schauer M, Gunter HM, Ruf-Leuschner M, Sill J, Meyer $A$, et al. Epigenetic modifications of the glucocorticoid receptor gene are associated with the vulnerability to psychopathology in childhood maltreatment. Transl Psychiatry. 2015;5:e571.

26. Coleman K, Pierre PJ. Assessing anxiety in nonhuman primates. ILAR J. 2014;55:333-46.

27. Lillycrop K, Burdge G. Epigenetic changes in early life and future risk of obesity. Int J Obes. 2011;35:72-83.

28. Lajud N, Torner L. Early life stress and hippocampal neurogenesis in the neonate: sexual dimorphism, long term consequences and possible mediators. Front Mol Neurosci. 2015;8:3.

29. Planalp EM, Braungart-Rieker JM. Trajectories of regulatory behaviors in early infancy: Determinants of infant self-distraction and self-comforting. Infancy. 2015;20:129-59.

30. Waite $P$, Creswell $C$. Observing interactions between children and adolescents and their parents: the effects of anxiety disorder and age. J Abnorm Child Psychol. 2015;43:1079-91.

31. Dallman MF. Stress-induced obesity and the emotional nervous system Trends Endocrinol Metab. 2010;21:159-65.

32. Pinto I, Wilkinson S, Virella D, Alves M, Calhau C, Coelho R. Attachment strategies and neuroendocrine biomarkers in obese children. Acta Med Port. 2016;29:332-9.

33. Pryor LE, Brendgen M, Tremblay RE, Pingault JB, Liu X, Dubois L, et al. Early risk factors of overweight developmental trajectories during middle childhood. PLoS One. 2015;10:e0131231.

34. Faravelli C, Lo Sauro C, Godini L, Lelli L, Benni L, Pietrini F, et al Childhood stressful events. HPA axis and anxiety disorders. World $\mathrm{J}$ Psychiatry. 2012;2:13-25.

35. Wilkinson S. Coping and complaining: attachment and the language of disease. Hove: Brunner-Routledge; 2003. 